\title{
EPIDEMIOLOGY OF TRAUMATIC BRAIN INJURY IN PEDIATRIC AND ADOLESCENT POPULATION IN COUNTRIES OF VISEGRAD GROUP
}

\author{
Juliana Melichová \\ MSc., Trnava University in Trnava, \\ e-mail: juliana.melichova@tvu.sk, orcid.org/0000-0003-4920-0778, Slovak Republic \\ Marek Majdan \\ Associate Professor, PhD., Trnava University in Trnava, \\ e-mail: mmajdan@truni.sk, orcid.org/0000-0001-8037-742X, Slovak Republic \\ Martin Rusnák \\ Professor MD, PhD., Trnava University in Trnava, \\ e-mail: martin.rusnak@truni.sk, orcid.org/0000-0003-3321-1042, Slovak Republic \\ Mark Steven Taylor \\ PhD., Trnava University in Trnava, \\ e-mail: marktrnava@gmail.com,orcid.org/0000-0002-7646-7905, Slovak Republic
}

\begin{abstract}
Traumatic brain injury (TBI) represents a substantial global and public health as well as a socio-economic problem. It is a common cause of death and disability and affects all age groups and sexes. Among the most vulnerable groups are boys, and adolescents under the age of 25 years. The most frequent causes of TBI are traffic accidents for young adults, and falls for both children and the elderly. The aim of the article is to document similarities and differences among four countries, to formulate a hypothesis for future policy interventions. The study is based on routine, publicly-accessible epidemiological monitoring data (deaths, hospital discharges, years of life lost) obtained from the Eurostat, the statistical office of the European Union. Data processing and analysis followed principles of a crosssectional, population-based epidemiological study. The highest rates were found in the Czech Republic and the lowest in Hungary. Based on the results, authors recognize the need for further efforts to improve the complexity of data, to develop preventive approaches and establish the research priorities. There are plans to initiate a new study based on our results, aiming to elucidate the roots for differences described.
\end{abstract}

Keywords: traumatic brain injuries, hospital discharges, mortality, YLL, children, young adults.

DOI: http://dx.doi.org/10.23856/3712

\section{Introduction}

Traumatic brain injury (TBI) is primarily related to cerebral dysfunction caused by external trauma. These injuries occur all over the world, representing substantial public health, medical, social, and economic issues in today's society (Peeters et al., 2015). Globally traumatic brain injuries are referred to as a 'silent epidemic' because the problems associated with these injuries are not immediately evident, and society underestimates their actual prevalence, impacts, and consequences. The contribution of TBI to worldwide death and disability can be greater than any other injuries (Dewan et al., 2018). TBIs also occur more frequently than many well-known diseases, including breast cancer, AIDS, Parkinson's disease, and multiple sclerosis (Namjoshi et al., 2013). 
Based on the latest estimated data from the World Health Organization (WHO), approximately 60 million people suffer from a traumatic brain injury worldwide. In European countries, it affects up to 2.5 million people annually, of which 1 million are admitted to hospital, and 75,000 die (CENTER-TBI, 2018).

As mentioned, traumatic brain injuries are a significant cause of mortality and morbidity, especially in children and adolescents. Children under 2 years of age, people aged 15 - 45 years and older adults aged 75 and over are most at risk. TBI can affect anyone, and are more common in boys compared to girls, with 1.4 higher incidence in boys aged $<10$ years old and 2.2 times higher incidence in boys aged $\geq 10$ years old (Maas, et al., 2017).

Brain injuries are also associated with decreased life expectancy. On average, one death as a result of traumatic brain injury is estimated to be equivalent to more than 24 years of life lost (Majdan, et al., 2017).

The most common causes of traumatic brain injuries are falls, road traffic incidents, following by physical assaults/violence, and sports-related injuries. Falls are becoming an increasingly common cause of brain injuries, especially in high-income regions of Europe, affecting the youngest $(0-4$ years $)$ and the oldest age groups (75 and over). Road traffic accidents are the leading cause of mortality in children and young adults aged $5-29$ years and working-age (30 - 44 years) (Yengo-Kahn et al., 2017).

Traumatic brain injuries are usually classified based on severity, anatomical trauma, and mechanism of injury. Symptoms of brain injury may be mild, moderate, or severe, depending on the extent of the injury. Mild TBIs occur in $80 \%$ of people, moderate in $10-$ $30 \%$ and severe traumatic brain injury in $5-25 \%$ of the population (CDC, 2015; Cassidy et al., 2004). Every year an estimated 300 people per 100,000 around the world undergo a medical examination on suspicion of having a mild traumatic brain injury. Many people with mild TBI do not seek medical help; therefore, their actual incidence likely exceeds 600 people per 100,000 per year, representing around 42 million people internationally every year (Gardner and Yaffe, 2015). Most injuries in children and adolescents are classified as mild brain damage $(80-90 \%)$. However, a significant number of children suffer moderate to severe injuries (Kim, et al., 2012). Most of the brain injury in children and adolescents do not require surgery; however, moderate to severe TBI requiring an operation is observed in 21 $63 \%$ of cases (Dewan et al., 2016).

Given the high rates of injuries in children and young adults, any accompanying consequences represent a significant health burden. The outcomes of traumatic brain injury, especially in children, are quite often discussed in the current literature (Lichte et al., 2015). Complications due to traumatic brain injury occur in most cases, immediately or shortly after the injury. Typical sequelae of moderate to severe TBI in children and young adults include physical complications (posttraumatic epilepsy, hydrocephalus, blood vessel damage, headache, insomnia, spastic hemiplegia, vertigo, tinnitus and polytrauma) emotional and behavioural disorders (depression, anxiety, risk behaviour, aggression) and cognitive (impaired school performance, memory disorders, difficulty concentrating, intellectual disability, posttraumatic speech disorder, dysarthria) (Ahmed et al., 2017; Goniewicz et al., 2017; Jorge, 2015). Most patients require physiotherapy, speech therapy, and younger adults, occupational therapy (Khattab and Othman, 2015).

The burden of brain injuries affects the daily lives of victims and their families, not to mention the enormous social and economic costs. A recent estimate of the total cost of treating traumatic brain injuries in Europe is $€ 33$ billion, while the direct and indirect cost in each individual with severe TBI has a cost estimate of nearly $€ 300,000$ (CENTER-TBI, 2019). 
Despite these alarming facts, the current epidemiological situation of traumatic brain injuries in Europe is not well known, especially among young children and adolescents.

To our knowledge, this issue, within European countries, has also been faced by the Czech Republic, Hungary, Poland and Slovakia; countries also known as the Visegrad Group or Visegrad Four (V4). This group, founded in 1993, forms a geographical unit of four eastern and central European states with a shared history and close socio-economic relations, representing efforts to cooperate on several sections of common interest within the framework of European-wide Integration (Visegradgroup, 2019). The estimation and comparison of epidemiological data, the examination of differences and similarities in epidemiology in V4 may help to improve data capture and formulate preventive programmes.

Therefore, the purpose of the research is to present a cross-sectional overview of the epidemiological patterns of traumatic brain injuries in children and young adults in the Visegrad countries.

\section{Methodology}

The study is designed as secondary data analysis - a cross-sectional, population-based epidemiological study. We used administratively collected data from Eurostat (European Statistical Office) for the year 2014, therefore no ethics committee approval was required. The data on our studied population of children and adolescents were stratified by country (the Visegrad Group of countries - the Czech Republic, Hungary, Poland and the Slovak Republic), sex and age (four categories covering a range from 0 to 19 years).

\section{Sources of data}

For analysis purposes, four datasets were obtained from Eurostat (deaths, hospital discharges, life expectancy, mid-year counts of countries).

The database on causes of death provides the necessary information on age, sex, country, primary and external causes of death. Data are being collected according to European regulation (OJ, 2011), and Eurostat annually verifies the validity of the causes of death indicators. Deaths related to traumatic brain injury are defined as deaths where their primary cause was TBI or an outcome of TBI. The inclusion criteria for primary causes of death are deaths falling under codes S00 - S09 (injuries to the head) and T90 (sequelae of injuries of head).

Primary causes of death due to TBI as defined by ICD-10

S00 Superficial injury of head

S01 Open wound of head

S02 Fracture of skull and facial bones

S03 Dislocation and sprain of joints and ligaments of head

S04 Injury of cranial nerve

S05 Injury of eye and orbit

S06 Intracranial injury

S07 Crushing injury of head

S08 Avulsion and traumatic amputation of part of head

S09 Other and unspecified injuries of head

T90 Sequelae of injuries of head

(WHO, 2016) 
The hospital discharge dataset provides the same information as death dataset, except for external causes. The primary causes of the patient's hospitalization were coded by International Shortlist for Hospital Morbidity Tabulation (ISHMT). Only those falling under codes S00 - S09 were included in the analysis (EUROSTAT-OECD-WHO, 2008).

A tertiary dataset on population counts of countries of V4 was extracted from Eurostat and stratified by sex and age, the same manner as the used fourth dataset on life expectancy.

Complete data were not possible to collect for all four countries. Overall, data on TBI related hospital discharge were available for all countries, but the death dataset was missing the actual number of deaths in Poland.

\section{Data analysis}

We used the obtained data to calculate three indicators for the overall analysis of the epidemiological situation of traumatic brain injury in children and young adults in the countries of the Visegrad group.

Firstly, we calculated crude rates, individually for hospital discharge and death. They were calculated as the number of demographic events recorded in the population over a given period divided by the population of the same period and recalculated to 100,000 population. As we deal in this study with specific cases in children and adolescents, we only used the age range from $0-19$ years, broken down into 4 groups $(0-4,5-9,10-14,15-19)$.

Subsequently, another epidemiological indicator was calculated - years of life lost (YLL) due to premature mortality. Children and young adults are given more significant emphasis, because the younger the age at which a person dies, the more the years of life are lost. The data needed to determine YLL were collected from a number of deaths from the database on causes of death and a database with standard life expectancy at the age of death in years (WHO, 2019).

The disadvantage of the crude rates is that they do not take into account the age specificities of the population and cannot be compared between particular countries; and was therefore used the direct method of standardisation to calculate the age-adjusted rates for hospital discharges, deaths and years of life lost. For comparison of population-based rates in direct age-adjustment, we applied the 2013 European standard population (theoretical population with age distribution based on actual age structure in the populations of European countries). To calculate pooled estimations, we used meta-regression.

\section{Results}

The main results of the data analysis on the epidemiological situation of traumatic brain injuries in children and young adults in the countries of the Visegrad Group are shown below.

\section{Hospital discharges}

In the course of the year 2014, we identified 67,785 TBI-related hospital discharges in the age group $0-19$ years. Boys accounted for $61 \%(41,319)$ and girls for $39 \%(26,466)$ (Table 1). The highest identified estimate of the indicator hospital discharge rates was in the age range $0-4$ years old, 683.1 per 100,000 people $(95 \% \mathrm{CI}: 507.5-858.7)$, with the rate of 744.2 (95\% CI: 556.0 - 932.5) in boys and 618.8 (95\% CI: $452.3-785.3$ ) in girls (Figure 1). Boy to girl rate ratio was 1.5 (95\% CI: $1.5-1.5)$, country ranging from 1.3 in Hungary to 1.5 in Poland (Table 2). 
Table 1

Distribution of TBI-associated hospital discharges, deaths and years of life lost by sex and age groups

\begin{tabular}{|c|c|c|c|c|c|c|}
\hline & $\begin{array}{r}\text { HC } \\
\text { DISC } \\
\mathbf{N}\end{array}$ & $\begin{array}{l}\text { AL } \\
\text { GES } \\
35\end{array}$ & \multicolumn{2}{|c|}{$\begin{array}{l}\text { DEATHS } \\
\quad \mathrm{N}=92\end{array}$} & \multicolumn{2}{|c|}{$\begin{array}{l}\text { YEARS OF LIFE LOST } \\
\qquad N=5,881\end{array}$} \\
\hline & \multicolumn{6}{|c|}{ Sex } \\
\hline & Boys & Girls & Boys & Girls & Boys & Girls \\
\hline \multicolumn{7}{|c|}{ Age groups } \\
\hline $0-4$ & $\begin{array}{l}12,709 \\
(57 \%)\end{array}$ & $\begin{array}{l}9,691 \\
(43 \%)\end{array}$ & $11(61 \%)$ & $7(39 \%)$ & 799 (59\%) & $552(41 \%)$ \\
\hline $5-9$ & $\begin{array}{l}8,650 \\
(62 \%)\end{array}$ & $\begin{array}{c}5,265 \\
(38 \%)\end{array}$ & $4(44 \%)$ & $5(56 \%)$ & $276(43 \%)$ & $370(57 \%)$ \\
\hline $10-14$ & $\begin{array}{c}8,380 \\
(62 \%)\end{array}$ & $\begin{array}{c}5,170 \\
(38 \%)\end{array}$ & $6(86 \%)$ & $1(14 \%)$ & $373(85 \%)$ & $68(15 \%)$ \\
\hline $15-19$ & $\begin{array}{l}11,580 \\
(65 \%)\end{array}$ & $\begin{array}{c}6,340 \\
(35 \%)\end{array}$ & $46(79 \%)$ & $12(21 \%)$ & $\begin{array}{c}2,674 \\
(78 \%)\end{array}$ & $769(22 \%)$ \\
\hline Total & $\begin{array}{c}41,319 \\
(61 \%)\end{array}$ & $\begin{array}{c}26,466 \\
(39 \%)\end{array}$ & $67(73 \%)$ & $25(27 \%)$ & $\begin{array}{c}4,122 \\
(70 \%)\end{array}$ & $\begin{array}{c}1,759 \\
(30 \%)\end{array}$ \\
\hline
\end{tabular}

Table 2

Boy-girl rate ratios of hospital discharge, mortality and years of life lost rates (95\% CI)

\begin{tabular}{|c|c|c|c|}
\hline \multirow{2}{*}{ COUNTRY } & $\begin{array}{c}\text { HOSPITAL } \\
\text { DISCHARGES }\end{array}$ & $\begin{array}{c}\text { bEARS OF LIFE } \\
\text { LOST }\end{array}$ \\
\cline { 2 - 4 } & & \multicolumn{3}{|c|}{ Rate ratios $(\mathbf{9 5 \%}$ CI) } \\
\hline Czech Republic & $1.4(1.3-1.4)$ & $2.9(2.0-4.2)$ & $3.7(3.4-4.0)$ \\
\hline Hungary & $1.3(1.2-1.4)$ & $2.3(1.6-3.5)$ & $1.2(1.1-1.3)$ \\
\hline Poland & $1.5(1.5-1.6)$ & not available & not available \\
\hline Slovak Republic & $1.5(1.4-1.6)$ & $1.8(1.2-2.8)$ & $1.5(1.3-1.7)$ \\
\hline Total & $\mathbf{1 . 5}(\mathbf{1 . 5}-\mathbf{1 . 5})$ & $\mathbf{2 . 5}(\mathbf{1 . 6}-\mathbf{4 . 1})$ & $\mathbf{2 . 2 ( 2 . 1 - 2 . 4 )}$ \\
\hline
\end{tabular}

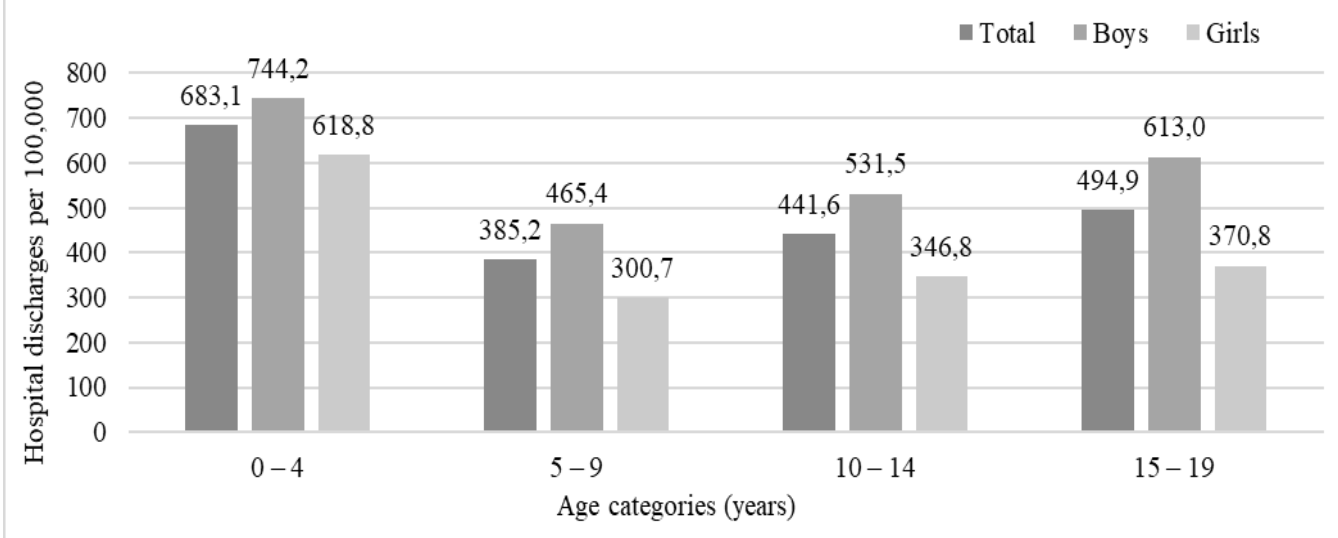

Figure 1. Crude hospital discharge rates resulting from traumatic brain injury by age 
The estimated pooled age-standardised hospital discharge rate was 497.0 per 100,000 (95\% CI: $377.7-616.3$ ). We identified the highest rate of this variable in the Czech Republic (651.8 [95\% CI: $640.8-662.9])$, and the lowest rate in Hungary (424.7 [95\% CI: 412.8 436.8]). The rates of hospital discharge were in all countries of V4 higher in boys in comparison with girls. The pooled age-adjusted hospital discharge rate in boys was 584.9 per 100,000 (95\% CI: 440.5 - 729.3), with country ranging from 433.8 (95\% CI: 421.0 - 446.9) in Hungary to 758.1 (95\% CI: $741.5-775.0)$ in the Czech Republic. The pooled age-adjusted rate in girls was 404.4 (95\% CI: 309.9 - 498.9), ranging from 329.3 (95\% CI: 317.9 - 341.0) in Hungary to 539.8 (95\% CI: 525.5 - 554.3) in the Czech Republic (Figure 2).

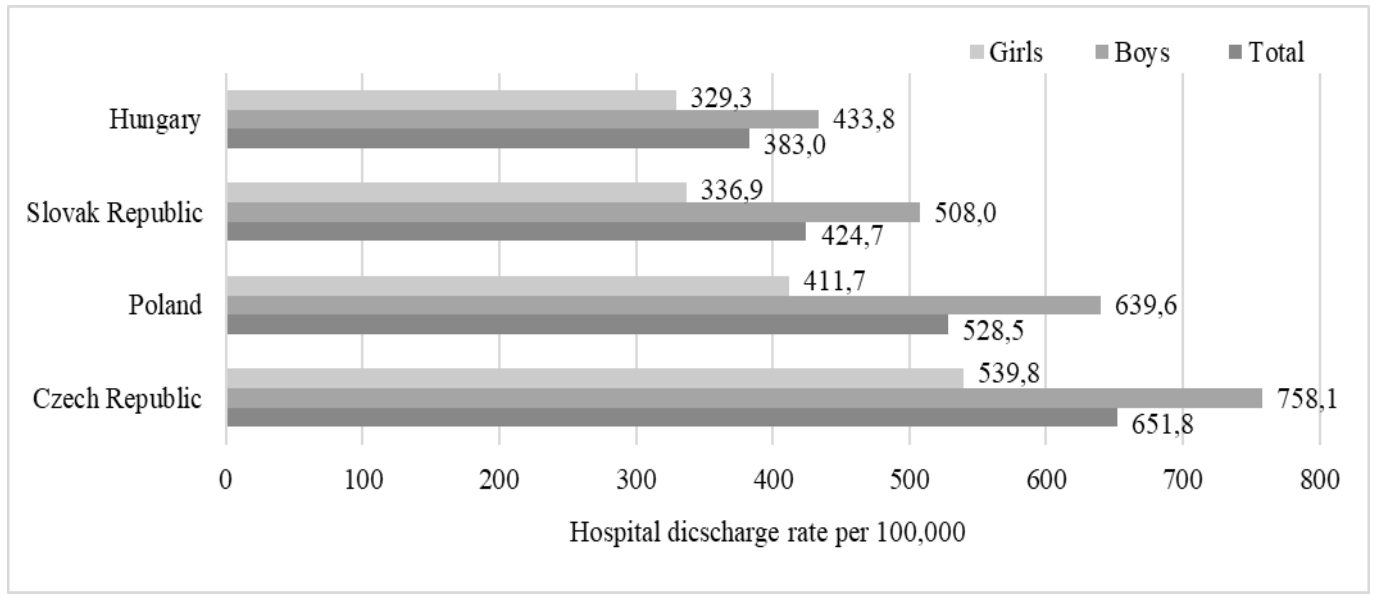

Figure 2. Age-standardised hospital discharge rates resulting from traumatic brain injury by country

\section{Deaths}

In the analysis of TBI-associated deaths and years of life lost, Poland was omitted, because the required information was not available for the studied year.

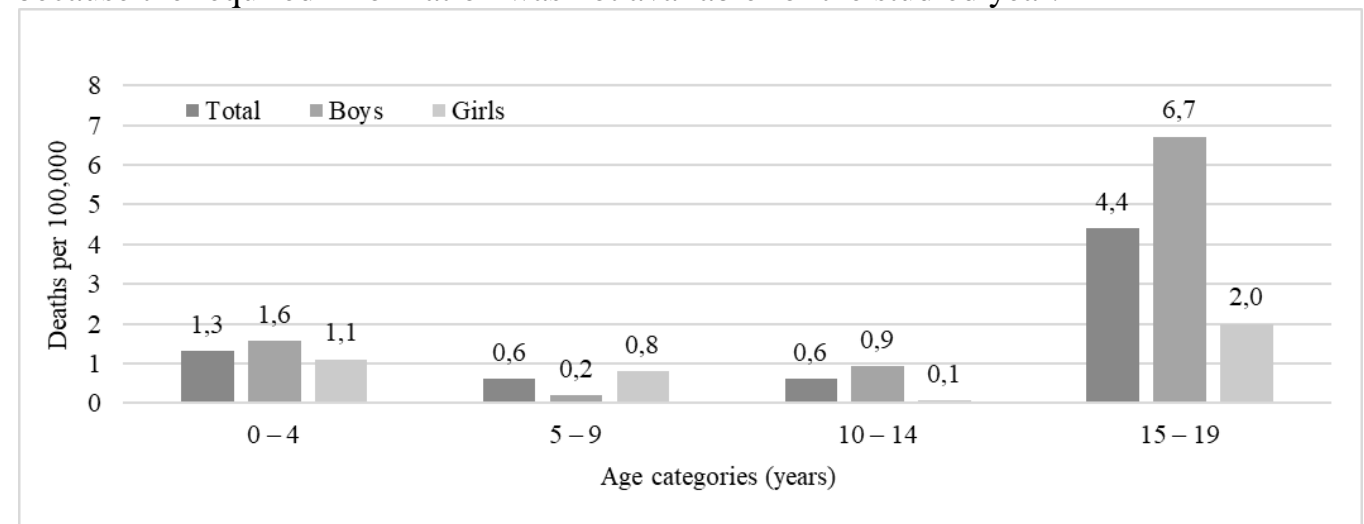

Figure 3. Crude mortality rates resulting from traumatic brain injury by age 
Injuries due to traumatic insult to the brain caused overall 92 deaths in children and young adults, of which boys accounted for 67 deaths (73\%) and girls for 25 deaths $(27 \%)$ (Table 1). Adolescents aged 15 to 19 showed the highest death rates with the estimate of 4.4 per 100,000 people (95\% CI: 2.0 - 6.8). In boys of this age, we identified the mortality rate of 6.7 (95\% CI: $2.4-11.0$ ) and in girls 2.0 (95\% CI: 1.3 - 2.7) (Figure 3). Boy to girl rate ratio was 2.5 (95\% CI: $1.6-4.1)$, ranging from 1.8 in the Slovak Republic to 2.9 in the Czech Republic (Table 2).

The pooled age-standardised death rate was estimated to be 1.7 per $100,000(95 \% \mathrm{CI}$ : $1.0-2.4)$, country rates ranging from $1.2(95 \%$ CI: $0.8-1.8)$ in Hungary to 2.5 (95\% CI: 1.9 - 3.3) in the Czech Republic. The evaluated age-adjusted mortality rates were again higher in boys $(2.4$ [95\% CI: $1.1-3.8])$ compared to girls (0.9 [95\% CI: $0.8-1.1])$. The analysed death rates in boys ranged from $1.4(95 \% \mathrm{CI}: 0.8-2.4)$ in Hungary to 4.1 (95\% CI: $2.9-5.5)$ in the Czech Republic. The estimated rates in girls ranged from 0.8 (95\% CI: $0.4-1.7)$ in the Czech Republic to 1.0 (95\% CI: $0.5-1.9$ ) in Hungary (Figure 4).

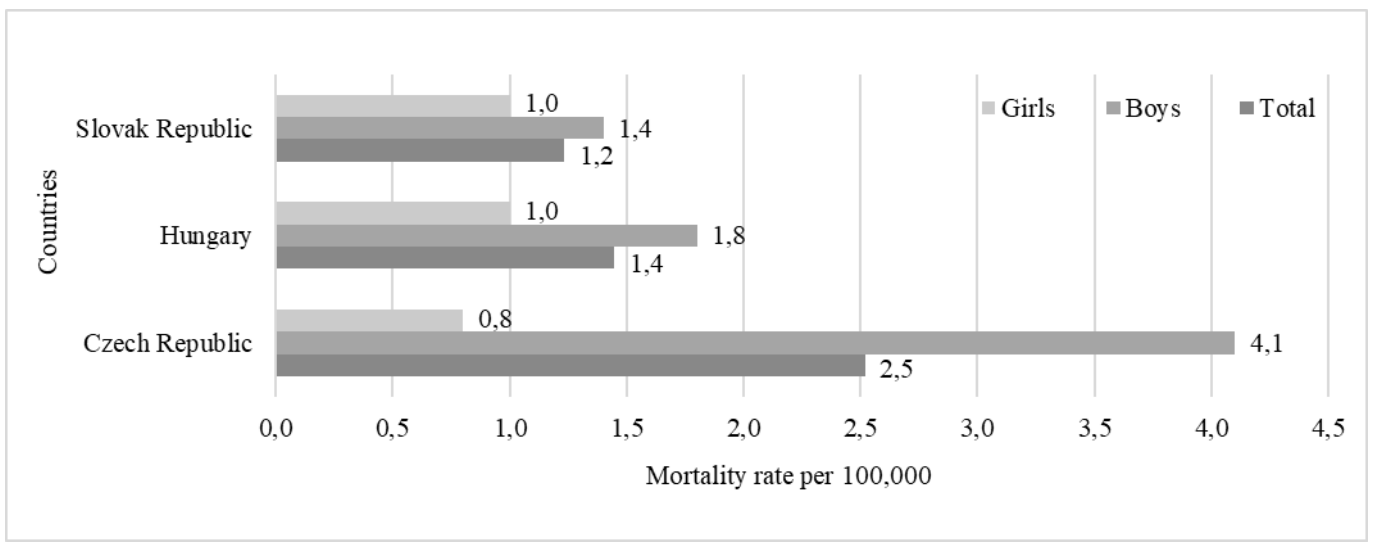

Figure 4. Age-standardised mortality rates resulting from traumatic brain injury by country

\section{Years of life lost}

Deaths due to traumatic brain injuries in the $0-19$ age group of the Visegrad Group countries resulted in 5881 YLL; 4,122 (70\%) in boys and 1,759 (30\%) in girls (Table 1). The highest number of years of life lost were estimated in the age category $15-19$ years old, 262.1 per 100,000 people (95\% CI: $110.3-413.8)$; 390.5 (95\% CI: 85.3 - 695.7) in boys and 126.9 (95\% CI: 82.6 - 171.2) in girls, respectively (Figure 5). Boy to girl rate ratio was 2.2 (95\% CI: $2.1-2.4$ ), ranging from 1.2 in Hungary to 3.7 in the Czech Republic (Table 2).

The pooled age-standardised years of life lost rate was 112.8 per 100,000 people $(95 \%$ CI: $65.7-159.9)$. The highest TBI-associated YLL rate was in the Czech Republic (165.5 [95\% CI: $159.9-171.3]$ ) and the lowest in Hungary (80.1 [95\% CI: $76.2-84.1])$. The burden of injury in YLL was found out to be higher in boys in comparison with girls. The pooled YLL rate in boys was 149.4 per 100,000 people (95\% CI: $61.2-237.6)$ and 68.8 (95\% CI: 63.0 - 74.6) in girls. The estimated YLL rates in boys ranged from 86.0 (95\% CI: $80.5-$ 91.8) in Hungary to 252.9 (95\% CI: 243.1 - 262.9) in the Czech Republic, and in girls from 
63.0 (95\% CI: $58.3-68.1$ ) in the Czech Republic to 71.8 (95\% CI: 66.5 - 77.3) in Hungary (Figure 6).

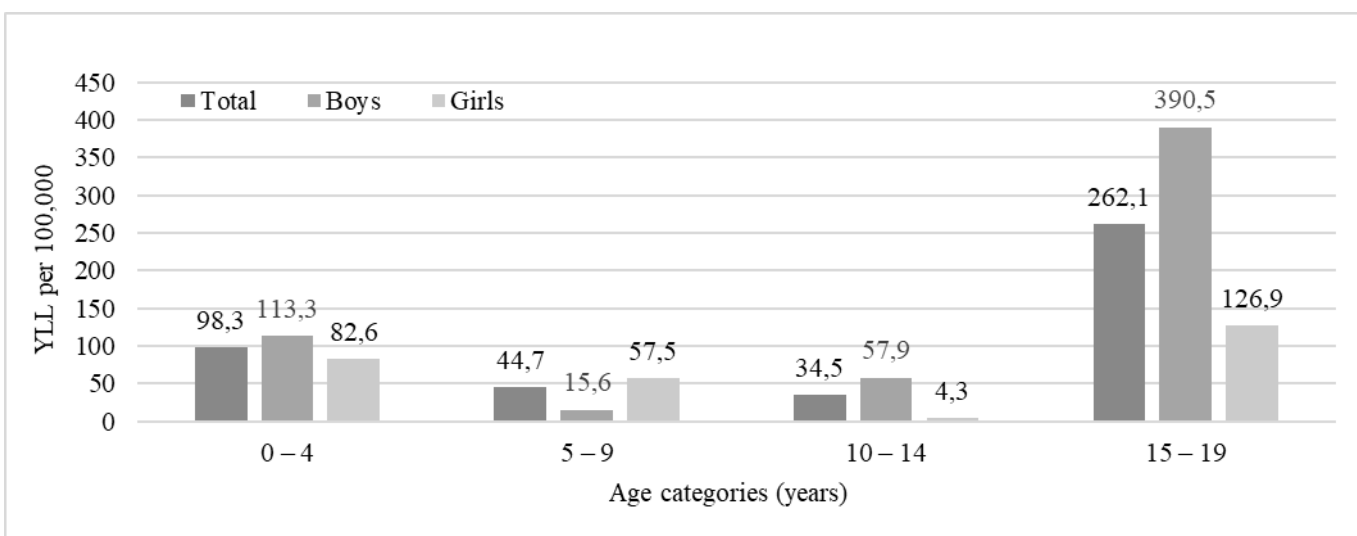

Figure 5. Crude years of life lost rates resulting from traumatic brain injury by age

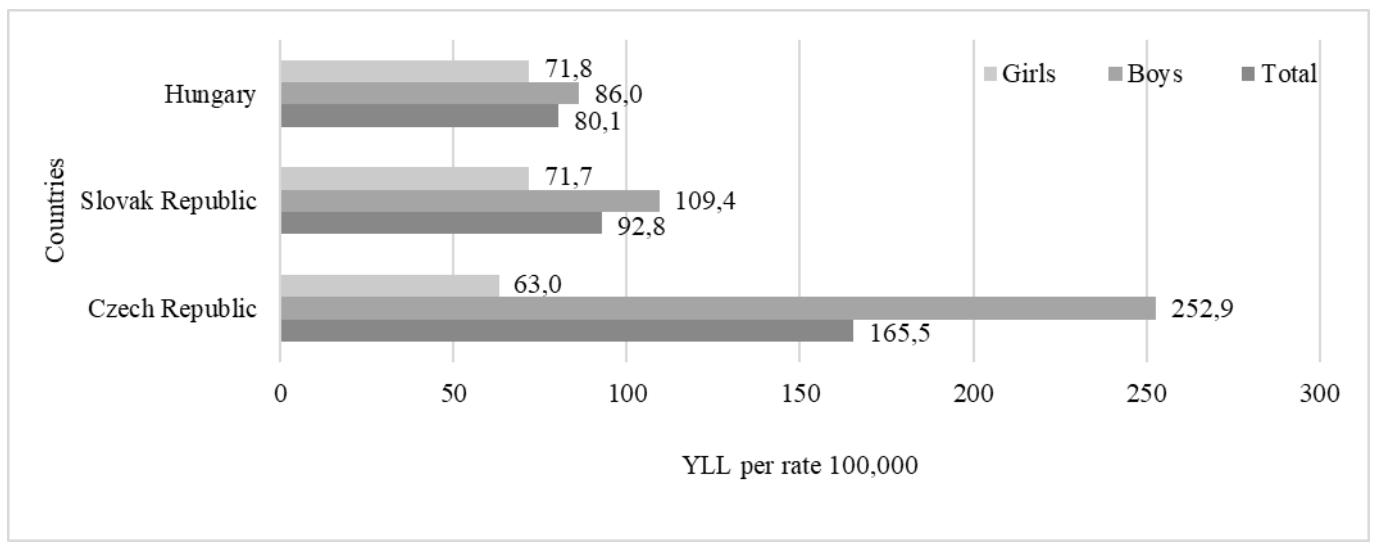

Figure 6. Age-standardised years of life lost rates resulting from traumatic brain injury by country

\section{Discussion}

There are significant differences in incidence and mortality rates within European populations. As mentioned, traumatic brain injuries occur more commonly in boys in comparison with girls. Our study results showed a similar situation in children and young adults in the countries of the Visegrad Group. In boys were identified higher pooled rates compared to girls in all analysed epidemiological indicators. However, we found some irregularities in one age category of individuals measured by sex. Age-adjusted rates of deaths (0.8) and years of life lost (57.7) were higher in girls of the age category 5 - 9 years, in comparison with boys in the same age category ( 0.2 and 15.6 , respectively). 
The same pattern of differences was observed in the analysed measures by country. The TBI-associated total pooled age-standardised rates and estimated rates in boys were highest in the Czech Republic and the lowest in Hungary. The interesting fact is that in girls the highest hospital discharge rate was identified in the Czech Republic (539.8), though the mortality rate and YLL rate in girls were in this country the lowest $(0.8,63.0$, respectively). The opposite was seen in girls in Hungary, where we identified the highest age-standardised mortality (1.0) and YLL (71.8) rates and the lowest hospital discharge rate (433.8). The considerable differences between countries in estimated analysed rates might be caused by the variations in coding and collecting of the necessary epidemiological data. The exception could be the data on the causes of death. Unlike hospital discharge rates, they are collected according to EU regulation, therefore are homogenous.

Current unresolved coding issues may cause troubles when comparing the incidence, prevalence, mortality, and other rates across countries (Dewan et al., 2018; Wilson, 2016). In order to analyse and determine the current situation effectively and adequately, it is crucial to have the necessary information to determine the overall occurrence of traumatic brain injuries accurately. Epidemiological research regarding traumatic brain injuries requires an accurate classification of the type of injury. The most generally used classification system is the International Classification of Diseases, 10th Revision (ICD-10), to classify and code cases to identify cases in individual administrative health databases (Barker-Collo et al., 2016).

In the year 2007, the Council of the European Union recommended that all Member States of the EU develop national injury-associated reporting systems and surveillance to monitor and observe injury trends and assess the effectiveness of injury prevention actions. Subsequently, the three-year project "Join Action on Monitoring Injuries in Europe (JAMIE)" was launched in 2011, the aim of which was to create a standard system for injury surveillance and prevention by 2015. The project involved 26 European countries collecting data on patients with injuries treated right on place of an accident or taken into hospitals. Currently, data is entered into the database by the EU Member States on a voluntary basis (Kirkwood, Hughes and Pollock, 2014).

Despite all established databases and registers, data on incidence, prevalence, mortality, hospital-based rate and other epidemiological indicators due to traumatic brain injuries are still insufficient. The primary cause is the mentioned inconsistency in using the international ICD-10 codes and not reporting pre-existing cases. In some of the European countries, there is no database that deals explicitly with traumatic brain injuries. Data on injuries, which is needed to analyse the state of injury in all age categories are obtained from available sources of individual ministries (e.g. Ministry of Health, Ministry of the Interior) (Maas, 2016; Chan, Thurairajah and Colantonio, 2015).

The understanding of the factors that determine the prognosis after traumatic brain injury is particularly useful in terms of research, policy-making and clinical practice. Fundamental predictors include demographic factors (age), type of injury, the severity of the injury and associated injuries. These factors may explain about $35 \%$ of the deviations in sequelae in a population with moderate and severe TBI. New predictive factors include genetics, biomarkers and results of magnetic resonance imaging (Maas, Lingsma and Roozenbeek, 2015). The consequences of brain injuries can be mitigated by the high quality of health care and rehabilitation, and the support of the family and the surrounding area plays an important role. Social and economic disparities affect the severity of the consequences of the injury if access to health care and treatment is not equally guaranteed for all social strata (Stoccheti and Zanier, 2016). 
Our study has limitations that we are aware of. The incomplete data as a consequence of coding issues and not reporting the cases from some countries can bias shown results. This gap can lead to underestimation or overestimation of the actual epidemiological situation of traumatic brain injuries.

\section{Conclusions}

The presented data can serve as an incentive for nationwide efforts to improve the acquisition of epidemiological data on TBI, formulate preventive strategies, define research priorities and support the services for patients living with traumatic brain injury (Maas, 2016).

There is evidence of a change in the epidemiology of traumatic brain injury, indicating the success of previous public health initiatives to reduce the road traffic-related TBIs, but this also underlines the need to recognise and understand the injuries occurring due to falls, especially in children and also the elderly (Popescu et al., 2015).

\section{References}

Ahmed, S., Venigalla, H., Mekala, H. M., Dar, S., Hassan, M., \& Ayub, S. (2017). Traumatic brain injury and neuropsychiatric complications. Indian Journal of Psychological Medicine. Medknow Publications, 39(2), 114-121. DOI:10.4103/0253-7176.203129. [in English].

Barker-Collo, S., Theadom, A., Jones, K., Feigin, V. L., \& Kahan, M. (2016). Accuracy of an International Classification of Diseases Code Surveillance System in the Identification of Traumatic Brain Injury. Neuroepidemiology, 47(1), 46-52. DOI:10.1159/000448403. [in English].

Cassidy, J. D., Carroll, L. J., Peloso, P. M., Borg, J., von Holst, H., Holm, L., Kraus, J., \& Coronado, V. G. (2004). Incidence, risk factors and prevention of mild traumatic brain injury: CDC. (2015). Guide to Writing About Traumatic Brain Injury in News and Social Media. [Electronic resource]. Retrieved from: https://www.cdc.gov/traumaticbraininjury/pdf/guideto-writing-about-tbi-in-news-and-social-media-a.pdf. [in English].

CENTER-TBI. (2018). A few facts about TBI. [Electronic resource]. Retrieved from: https://www.center-tbi.eu/. [in English].

CENTER-TBI. (2019). Project. [Electronic resource]. Retrieved from: https://www.centertbi.eu/project/background. [in English].

Chan, V., Thurairajah, P., \& Colantonio, A. (2015). Defining pediatric traumatic brain injury using International Classification of Diseases Version 10 Codes: a systematic review. BMC Neurology, 15, 7-015-0259-7. DOI: 10.1186/s12883-015-0259-7. [in English].

Dewan, M. C., Mummareddy, N., Wellons, J. C., \& Bonfield, C. M. (2016). Epidemiology of Global Pediatric Traumatic Brain Injury: Qualitative Review. World Neurosurgery. Elsevier Inc., 91, 497-509. DOI:10.1016/j.wneu.2016.03.045. [in English].

Dewan, M. C., Rattani, A., Gupta, S., Baticulon, R. E., Hung, Y., Punchak, M., Agrawal, A., Adeleye, A. O., Shrime, M. G., Rubiano, A. M., Rosenfeld, J. V., \& Park, K. B. (2018). Estimating the global incidence of traumatic brain injury, Journal of Neurosurgery JNS, 130(4), 1080-1097. DOI:10.3171/2017.10.JNS17352. [in English].

Eurostat - OECD - WHO. (2008). International shortlist for hospital morbidity tabulation (ISHMT). [Electronic resource]. Retrieved from: http://apps.who.int/classifications/apps/icd/implementation/hospitaldischarge.htm. [in English]. 
Gardner, R. C., \& Yaffe, K. (2015). Epidemiology of mild traumatic brain injury and neurodegenerative disease. Molecular and Cellular Neuroscience. Academic Press Inc.,66, 75-80. DOI:10.1016/j.mcn.2015.03.001. [in English].

Goniewicz, K., Goniewicz, M., Pawloswski, W., Fiedor, P., \& Lasota, D. (2017). Risk of road traffic accidents in children. Medical Studies, 33(2), 155-160. DOI:10.5114/ms.2017.68712. [in English].

ISD Scotland. (2010). European Standard Population 2013. [Electronic resource]. Retrieved from: https://www.isdscotland.org/Products-and-Services/GPD-Support/Population/ Standard-Populations/. [in English].

Jorge, R. (2015). Mood disorders. Handbook of Clinical Neurology, 128, 613-631. DOI:10.1016/B978-0-444-63521-1.00038-8. [in English].

Khattab, A., \& Othman, Y. (2015). The outcome of severe traumatic brain injury in children in Qatar: Six-year study. Journal of Local and Global Health Science. DOI:10.5339/jlghs.2015.itma.29. [in English].

Kim, H. B., Kim, D. K., Kwak, Y. H., Shin, S. D., Song, K. J., Lee, S. C., Park, J., Jang, H., \& Kim, S. C. (2012). Epidemiology of traumatic head injury in Korean children. Journal of Korean Medical Science, 27(4), 437-442. DOI:10.3346/jkms.2012.27.4.437. [in English].

Kirkwood, G., Hughes, T. C., \& Pollock, A. M. (2014). Injury surveillance in Europe and the UK. BMJ Publishing Group. DOI:10.1136/bmj.g5337. [in English].

Lichte, P., Andruszkow, H., Kappe, M., Horst, K., Pishnamaz, M., Hildebrand, F., Lefering, R., Pape, H., \& Kobbe, P. (2015). Increased in-hospital mortality following severe head injury in young children: Results from a nationwide trauma registry. European Journal of Medical Research, 20(1). DOI:10.1186/s40001-015-0159-8. [in English].

Maas, A. I. R. (2016). Traumatic brain injury in India: A big problem in need of data. Neurology India, 6(2), 65-69. DOI:10.4103/0028-3886.20184. [in English].

Maas, A. I. R., Lingsma, H. F., \& Roozenbeek, B. (2015). Predicting outcome after traumatic brain injury. In Handbook of Clinical Neurology, 128, 455-474. Elsevier B.V. DOI:10.1016/B978-0-444-63521-1.00029-7. [in English].

Maas, A. I. R., Menon, D., Adelson, P. D., Andelic, N., Bell, M. J., Belli, A., Bragge, P., et al. (2017). Traumatic brain injury: integrated approaches to improve prevention, clinical care, and research.. The Lancet Neurology, 16(12), 987-1048. DOI:10.1016/S14744422(17)30371-X. [in English].

Majdan, M., Plančiková, D., Maas, A. I. R., Polinder, S., Feigin, V.L., Theadom, A., Rusnak, M., Bražinová, A., \& Haagsma, J. (2017). Years of life lost due to traumatic brain injury in Europe: A cross-sectional analysis of 16 countries. PLoS medicine, 14(7). DOI:10.1371/journal.pmed.1002331. [in English].

Namjoshi, D. R., Good, C., Cheng, W. H., Panenka, W., Richards, D., Cripton, P. A., \& Wellington, CH. L. (2013). Towards clinical management of traumatic brain injury: a review of models and mechanisms from a biomechanical perspective. Disease Models \& Mechanisms, 2013(6), 1325-1338. DOI: 10.1242/dmm.011320. [in English].

OJ. (2011). COMMISSION REGULATION (EU) No 328/2011 of 5 April 2011 implementing Regulation (EC) No 1338/2008 of the European Parliament and of the Council on Community statistics on public health and health and safety at work, as regards statistics on causes of death. [Electronic resource]. Retrieved from: https://eur-lex.europa.eu/LexUriServ/ LexUriServ.do?uri=OJ:L:2011:090:0022:0024:EN:PDF. [in English]. 
Peeters, W., van den Brande, R., Polinder, S., Brazinova, A., Steyerberg, E. W., Lingsma, $H$. F., \& Maas, A. I. R. (2015). Epidemiology of traumatic brain injury in Europe. Acta neurochirurgica, 157(10), 1683-1696. DOI:10.1007/s00701-015-2512-7. [in English].

Popescu, C., Anghelescu, A., Daia, C., \& Onose, G. (2015). Actual data on epidemiological evolution and prevention endeavours regarding traumatic brain injury. Journal of Medicine and Life, 8(3), 272-277. [in English].

Results of the WHO Collaborating Centre Task Force on Mild Traumatic Brain Injury. Journal of Rehabilitation Medicine, Supplement, 36 (43). doi:10.1080/16501960410023732. [in English].

Stocchetti, N., \& Zanier, E. R. (2016). Chronic impact of traumatic brain injury on outcome and quality of life: A narrative review. Critical Care. BioMed Central Ltd. DOI:10.1186/s13054-016-1318-1. [in English].

Visegradgroup. (2019). About the Visegrad Group [Electronic resource]. Retrieved from: http://www.visegradgroup.eu/about. [in English].

WHO. (2016). ICD-10 Version:2016. [Electronic resource]. Retrieved from: https://icd.who.int/browse10/2016/en\#/S00-S09. [in English].

WHO. (2016). ICD-10 Version:2016. [Electronic resource]. Retrieved from: https://icd.who.int/browse10/2016/en\#/T90-T98. [in English].

WHO. (2019). Metrics: Disability-Adjusted Life Year (DALY). [Electronic resource]. Retrieved from: https://www.who.int/healthinfo/global_burden_disease/metrics_daly/en/. [in English].

Wilson, M. H. (2016). Traumatic brain injury: an underappreciated public health issue. The Lancet Public Health. Elsevier Ltd. DOI:10.1016/S2468-2667(16)30022-6. [in English].

Yengo-Kahn, A. M., Gardner, R. M., Kuhn, A. W., Solomon, G. S., Bonfield, C. M., \& Zuckerman, S. L. (2017). Sport-Related Structural Brain Injury: 3 Cases of Subdural Hemorrhage in American High School Football. World Neurosurgery, 106, 1055.e51055.e11. DOI:10.1016/j.wneu.2017.07.072. [in English]. 